\title{
PENGEMBANGAN POTENSI BUAH KECOMBRANG (Etlingera elatior) MENJADI “SIALA JELLY” DI DESA SIMATOHIR
}

\author{
Yusnita Wahyuni Silitonga, Rafiqah Amanda, Muhammad Nizar Hanafiah \\ Nasution, Amir Mahmud, Irmalia Fitri \\ Program Studi Agroteknologi, Fakultas Pertanian, Universitas Muhammadiyah Tapanuli Selatan, \\ Sumatera Utara \\ nizarhanafiah.12@gmail.com
}

\begin{abstract}
Kecombrang is a type of shrub that can be found in the gardens of Simatohir villagers. In Simatohir village, kecombrang flowers have been processed into processed food such as kecombrang sticks, but the fruit has not been utilized optimally. Several studies have shown that kecombrang has much efficacy, especially in preventing and treating various diseases, so that kecombrang can be used as a functional food. This activity aims to increase the potential of kecombrang (Etlingera elatior) fruit by using it as food processing (siala jelly) to improve the welfare of the local community. This activity is carried out in several stages, namely establishing cooperation with the local government, preliminary testing of the manufacture of kecombrang processing, socialization, and assistance for kecombrang processing. The socialization of siala jelly in the Simatohir village runs very well, seen from the participants' enthusiasm in listening to the material and asking a few questions. The results of the questionnaire given to the participants showed that all participants liked the taste of the siala jelly.
\end{abstract}

Keywords: Kecombrang, functional food, Desa Simatohir

\begin{abstract}
Abstrak
Kecombrang merupakan jenis tanaman semak yang banyak ditemukan di kebun masyarakat desa Simatohir. Di desa Simatohir bunga kecombrang sudah pernah diolah menjadi olahan pangan seperti Stick kecombrang, tapi buahnya belum termanfaatkan secara maksimal. Dari beberapa penelitian menunjukkan bahwa kecombrang memiliki banyak khasiat khususnya dalam mencegah dan mengobati beragam penyakit sehingga kecombrang dapat dijadikan sebagai pangan fungsional. Kegiatan ini bertujuan untuk meningkatkan potensi buah kecombrang (Etlingera elatior) dengan pemanfaatannya menjadi olahan pangan (siala jelly) sebagai upaya meningkatkan kesejahteraan masyarakat setempat. Kegiatan ini dilaksanakan dalam beberapa tahap yaitu menjalin kerja sama dengan pemerintah daerah setempat, uji pendahuluan pembuatan olahan kecombrang, Sosialisasi dan pendampingan pengolahan kecombrang. Kegiatan sosialisasi pembuatan siala jelly kepada masyarakat desa Simatohir berjalan dengan lancar dilihat dari antusias peserta dalam menyimak materi dan mengajukan beberapa pertanyaan. Hasil kuisoner yang diberikan kepada peserta menunjukkan bahwa semua peserta menyukai rasa siala jelly.
\end{abstract}

Kata kunci: Kecombrang, Pangan Fungsional, Desa Simatohir 


\section{PENDAHULUAN}

Dimasa pandemi Covid 19 ini kesadaran masyarakat terhadap kesehatan semakin meningkat. Bahan pangan yang kini banyak diminati konsumen bukan saja yang mempunyai komposisi gizi yang baik serta penampakan dan cita rasanya menarik, tetapi juga harus memiliki fungsi fisiologis tertentu bagi tubuh. Salah satu bahan pangan yang dapat dijadikan sebagai pangan fungsional adalah kecombrang (Etlinera elatior). Kecombrang dapat dijadikan bahan pangan fungsional karena dapat mencegah dan mengobati beberapa penyakit seperti menurunkan tekanan darah, kadar kolestrol, kadar gula darah dan antibakteri (Naufalin, 2005).

Kecombrang merupakan jenis tanaman semak yang banyak ditemukan di kebun masyarakat desa Simatohir. Kecombrang biasanya dijadikan sebagai rempah atau bumbu masakan. Di desa Simatohir bunga kecombrang sudah pernah diolah menjadi olahan pangan seperti Stick kecombrang Tapi buahnya belum termanfaatkan secara maksimal sehingga diharapkan pembuatan pangan dari kecombrang ini dapat meningkatkan kesejahteraan masyarakatnya. Pada kegiatan ini buah kecombrang akan diolah menjadi "Siala Jelly”

Dari hasil survey pertama (Januari 2020) di Desa Simatohir Kecamatan Angkola Julu yang berjarak kurang lebih $10 \mathrm{~km}$ dari Universitas Muhammadiyah Tapanuli Selatan. Di desa tersebut terdapat 7 kelompok tani yang tergabung dalam Gapoktan Suka
Damai, dari ketujuh kelompok tani tersebut terdapat satu kelompok wanita tani yang cukup aktif yaitu kelompok wanita tani Al-ikhsan dan satu kelompok PKK. Ditinjau dari aspek tekhnis permasalahan yang timbul di Desa Simatohir adalah potensi sumber daya manusianya yang masih terbatas dan tingkat pendidikannya yang masih rendah serta kurangnya pengetahuan dalam hal pengolahan hasil pertanian

Program pengabdian kepada masyarakat melalui pedampingan kelompok tani desa Simatohir bertujuan meningkatkan potensi buah kecombrang dengan pemanfaatannya menjadi olahan pangan sebagai upaya untuk meningkatkan kesejahteraan masyarakat setempat. Manfaat yang diharapkan dari kegiatan ini adalah informasi dan ilmu pengetahuan bagi masyarakat tentang pengolahan buah kecombrang menjadi olahan pangan.

\section{METODE PELAKSANAAN}

\section{A. Menjalin Kerja Sama dengan Pemerintah dan Masyarakat}

Kegiatan ini diawali dengan menjalin kerja sama dengan pemerintah dan masyarakat desa Simatohir. Kegiatan ini melibatkan kelompok wanita tani Al-ikhsan dan Ibu PKK.

\section{B. Uji Pendahuluan Pengolahan Pangan dari Kecombrang}

Uji pendahuluan pengolahan Siala Jelly bertujuan untuk mengetahui komposisi bahan yang sesuai untuk pengolahan siala jelly. Komposisi yang 
diuji adalah takran gula dan agar yang digunakan paling sesuai

\section{Cara Pengolahan Siala Jelly}

Pertama kikis kulit luar buah kecombrang kemudian dicuci hingga benar-benar bersih. Buah kecombrang dibelah dua sampai biji yang ada di dalam buah kecombrang dapat diambil dengan mudah. Selanjutnya Kulit dan biji buah kecombrang di haluskan dengan blender. Masukkan buah kecombrang yang telah disaring ke dalam panci, tambahkan gula pasir dan agar plain sesuai takaran dan direbus hingga mendidih, selanjutnya dikemas.

\section{Sosialisasi Pengolahan Kecombrang}

Sosialisasi bertujuan untuk memberikan informasi tentang pemanfaatan buah kecombrang menjadi siala jelly. Selain cara pembuatannya pada tahap ini juga dijelaskan bagaimana potensi dan prospek siala jelly kedepan sebagai upaya meningkatkan kesejahteraan masyarakat.

\section{Pendampingan Pembuatan Pangan dari Kecombrang}

Pendampingan pembuatan jelly buah kecombrang pada kelompok wanita tani Al-iksan bertujuan untuk memastikan apakah Anggota kelompok wanita tani tersebut benar-benar sudah bisa dalam pembuatan siala jelly.

\section{HASIL DAN PEMBAHASAN}

\section{A. Jadwal Kegiatan}

Kegiatan ini diawali dengan dengan menjalin kerja sama dengan pemerintah dan masyarakat desa Simatohir. Kegiatan ini melibatkan kelompok wanita tani Al-ikhsan tani yang cukup aktif dalam kegiatan usaha tani.

Kegiatan ini dilaksanakan di
kantor kepala Desa Simatohir
Kecamatan Padangsidimpuan Angkola
Julu Kota Padangsidimpuan. Dalam
menentukan jadwal kegiatan, tim
pelaksana PKM bersepakat dengan
mitra. Jadwal kegiatan dapat dilihat
pada tabel 1 .

Tabel 1. Jadwal Kegiatan

\begin{tabular}{clc}
\hline No & \multicolumn{1}{c}{ Kegiatan } & Jadwal \\
\hline 1 & $\begin{array}{l}\text { Survey lokasi dan menjalin hubungan dengan } \\
\text { pemerintah atau ketua kelompok tani Al-ikhsan } \\
\text { dan Kelompok PKK }\end{array}$ & Juni 2020 \\
2 & Uji Pendahuluan Pengolahan Pangan dari & Oktober 2020 \\
3 & Kecombrang & Desember 2020 \\
4 & Sosialisasi pembuatan olahan kecombrang & Desember 2020 \\
5 & Pelatihan pembuatan olahan kecombrang & Desember 2020 \\
6 & Publikasi & Desember 2020 \\
\hline
\end{tabular}





\section{Hasil Survey ke Desa Simatohir}

Dari hasil survey pertama di

Desa Simatohir Kecamatan Angkola Julu yang berjarak kurang lebih $10 \mathrm{~km}$ dari Universitas Muhammadiyah Tapanuli Selatan. Di desa tersebut terdapat 7 kelompok tani yang tergabung dalam Gapoktan Suka Damai, dari ketujuh kelompok tani tersebut terdapat satu kelompok wanita tani yang cukup aktif yaitu kelompok wanita tani Al-Ikhsan. Ditinjau dari aspek tekhnis permasalahan yang timbul di Desa Simatohir adalah potensi sumber daya manusianya yang masih terbatas dan tingkat pendidikannya yang masih rendah serta kurangnya pengetahuan dalam hal pengolahan hasil pertanian.

Kelompok Wanita Tani AlIkhsan memiliki beberapa usaha pertanian salah satunya adalah pembibitan tanaman sayur. Pembibitan dilakukan di dalam rumah kasa yang merupakan bantuan dari dana desa. Usaha pembibitan belum maksimal karena ilmu mengenai teknik pembibitan anggota KWT masih minim. Proses pembibitan masih sering gagal akan tetapi beberapa bibit masih bisa dimanfaatkan.

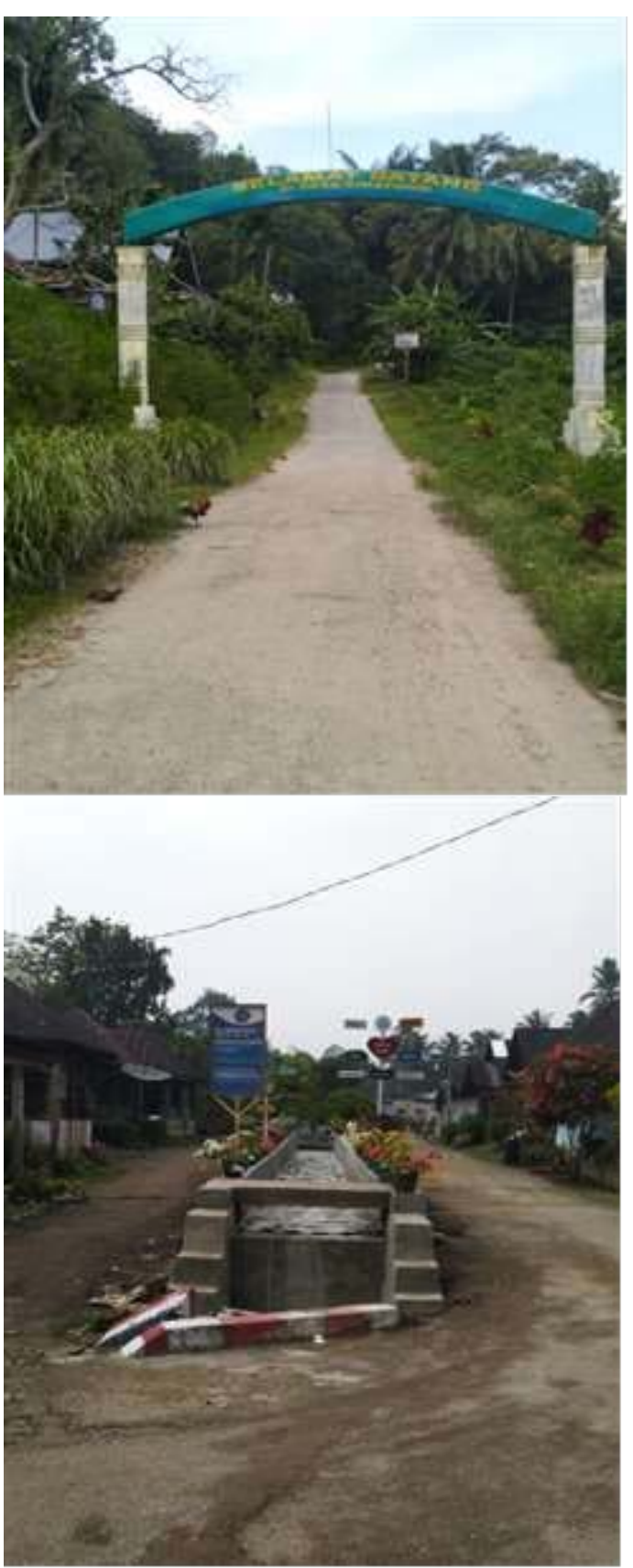

Gambar 1. Desa Simatohir

Usaha KWT Al-Ikhsan belum produktif dalam bidang pengolahan pangan. Banyak hasil pertanian yang dijual dalam bentuk buah bahkan dibiarkan dipohon sampai busuk. Jika hasil pertanian diolah menjadi olahan pangan dapat dipastikan keuntungannya lebih maksimal. Salah satu contoh tanaman pertanian yang tidak 
dimanfaatkan adalah kecombrang. Tanaman kecombrang banyak ditemukan di desa simatohir bahkan di sekitar rumah warga banyak ditemukan. Tanaman ini masih dianggap warga sebagai gulma karena belum mengetahui manfaat dan cara pengolahannya. Untuk meningkatkan nilai ekonomis dari tanaman kecombrang ini maka perlu dilakukan sosialisasi mengenai manfaat dan cara pengolahan bunga dan buah kecombrang.

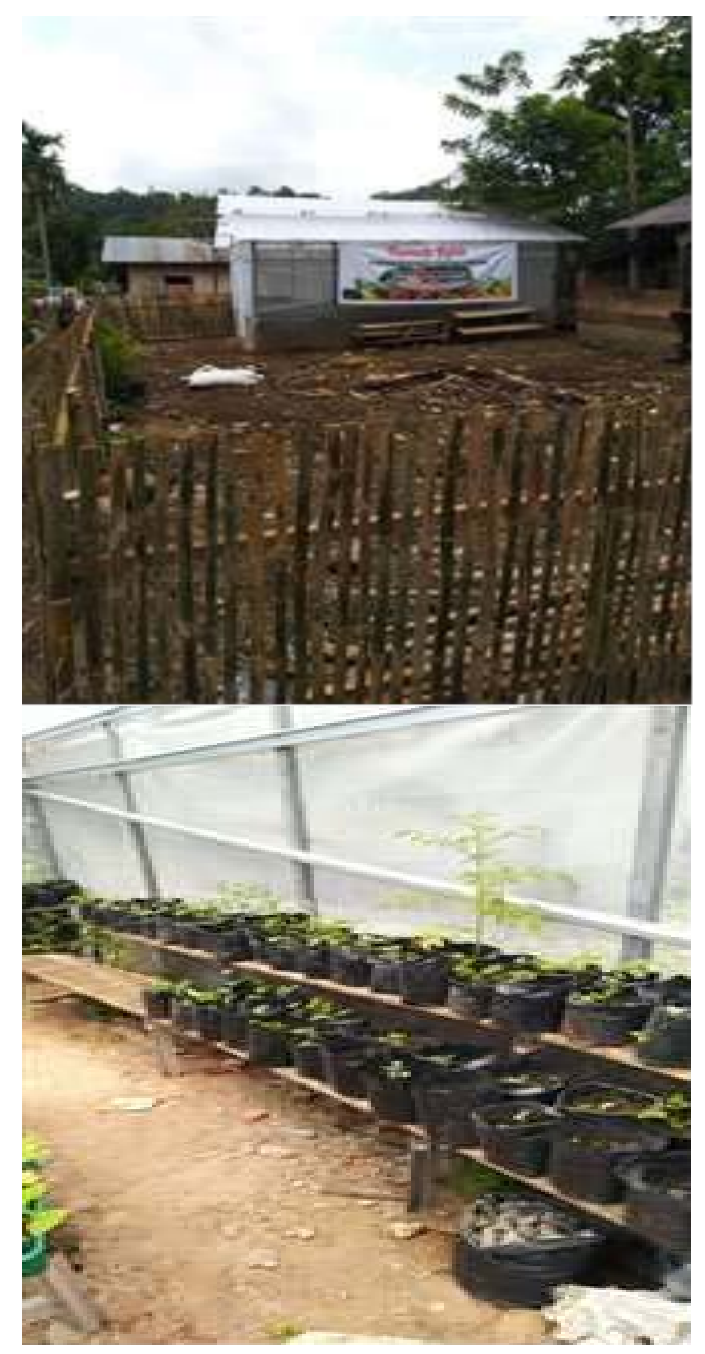

Gambar 2. Rumah kasa tempat pembibitan KWT Al-ikhsan

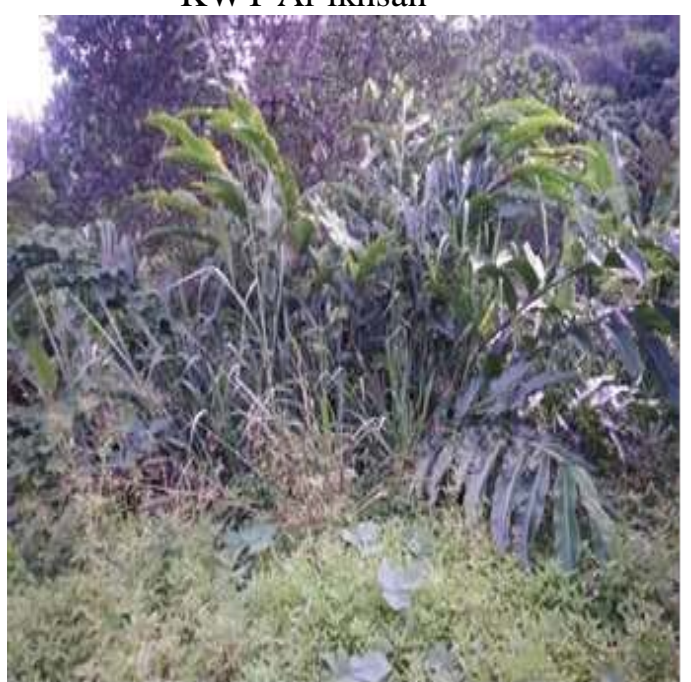

Gambar 3. Tanaman kecombrang masih dianggap gulma

\section{B. Pelaksanaan Kegiatan}

1. Uji Pendahuluan Pengolahan Siala Jelly

Uji pendahuluan pengolahan stick bertujuan untuk mengetahui komposisi bahan yang sesuai untuk olahan siala jelly. Komposisi yang diuji adalah perbandingan takaran buah kecombrang, air, gula dan agar plain yang digunakan.

Dari hasil uji coba Komposisi bahan yang paling sesuai untuk olahan stick kecombrang adalah dalam $2 \mathrm{~L}$ air ditambahkan 500 g kecombrang, 500 g gula pasir dan 3 bungkus agar plain (1 bungkus isi $15 \mathrm{~g}$ ) 



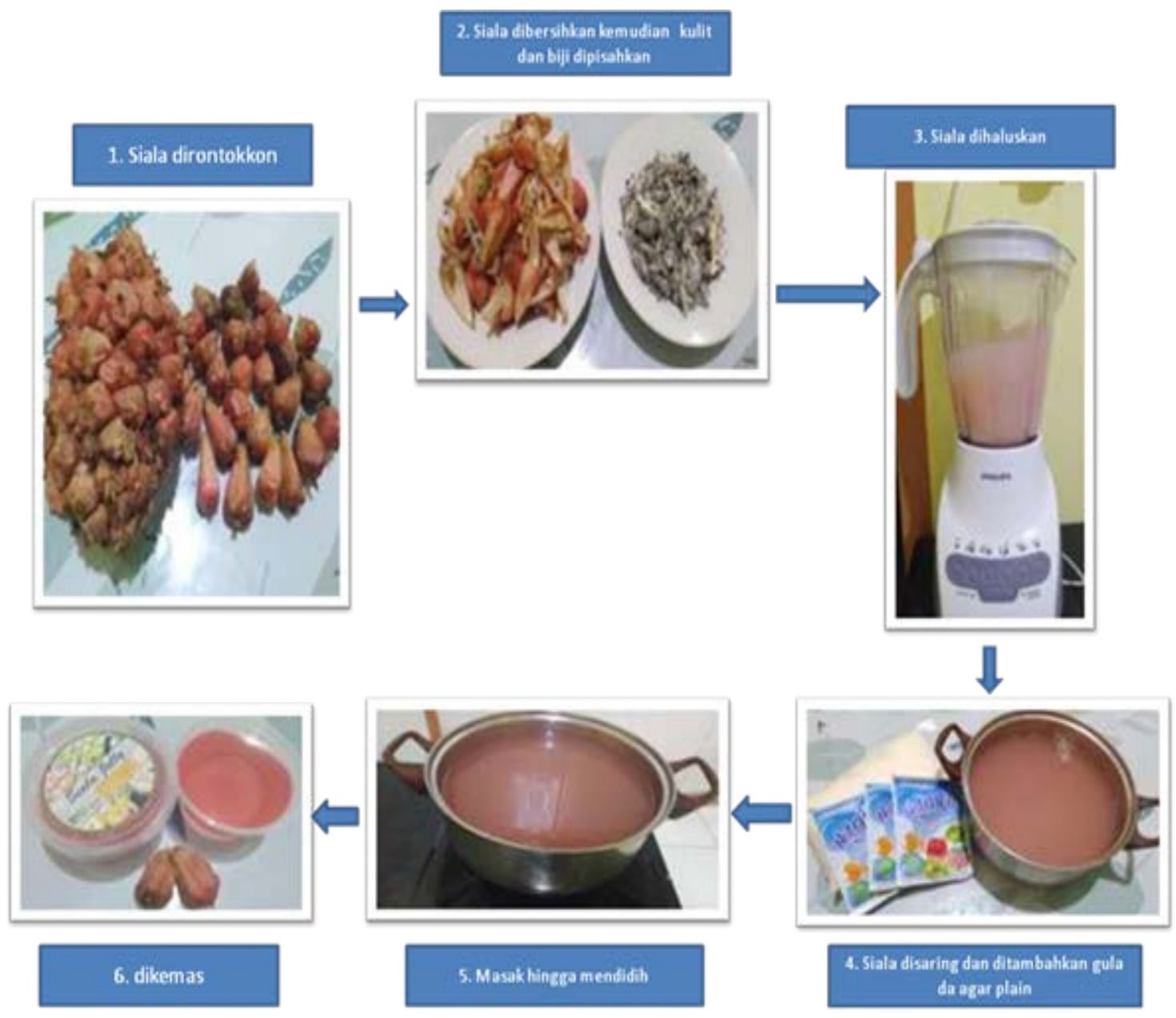

Gambar 4. Prosedur Pembuatan Siala Jelly

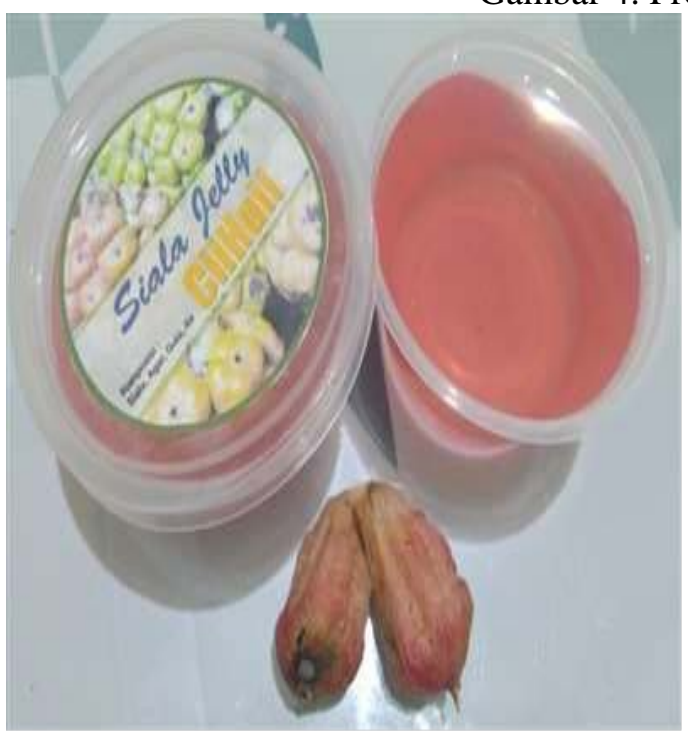

Gambar 5. Siala Jelly

Siala jelly dikatakan pangan fungsional karena kandungan buah kecombrang pada siala jelly memberikan keuntungan bagi kesehatan. Pangan Fungsional bermanfaat untuk mencegah penyakit, memperlambat proses penuaan dan meningkatkan imunitas (Hudaya, 2010). Banyak jenis pangan fungsional yang beredar di pasaran seperti yoghurt dan berbagai minuman yang mengandung komponen aktif rempah-rempah seperti jahe dan kunyit

\section{Sosialisasi Olahan Siala Jelly}

Kegiatan sosialisaasi dilaksanakan di kantor kepala desa Simatohir pada bulan Desember 2020. Kegiatan sosialisasi diawali dengan pembacaan ayat suci Alquran oleh mahasiswa pertanian UMTS kemudian 
dilanjutkan dengan kata sambutan dari ketua KWT Al-ikhsan Simatohir untuk mengetahui permasalahan yang dihadapi pada pada produk salak khususnya. Ketua KWT Al-ikhsan tersebut menyampaikan bahwa masalah terbesar yang mereka alami adalah bagaimana cara pemanfatan kecombrang agar lebih bernilai ekonomis.

Sosialisasi Siala jelly disampaikan oleh ketua pelaksana, dalam sosialisasi tersebut peserta sangat antusias dapat dilihat dari keseriusan mereka memperhatikan penyampaian materi

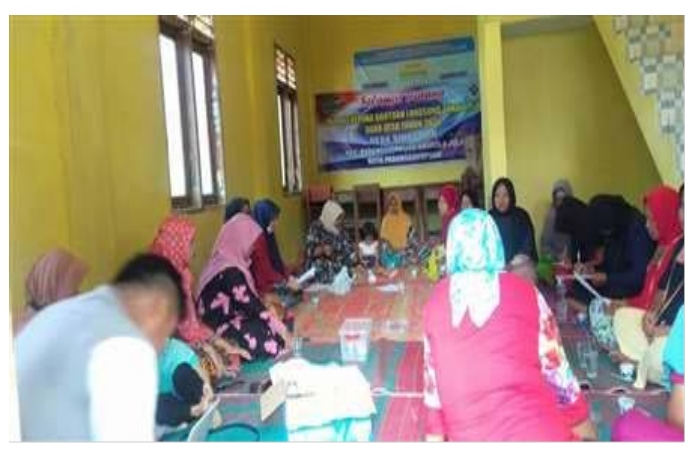

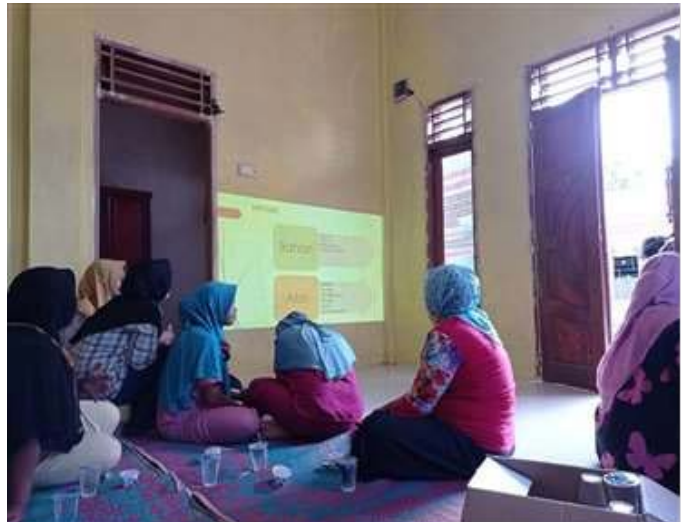

Gambar 6. Kegiatan Sosialisasi

Hasil sosialisasi siala jelly pada masyarakat menunjukkan respon yang baik. Respon masyarakat tersebut dapat dijadikan sebagai dasar bahwa siala jelly dapat dijadikan sebagai olahan dari buah siala yang selama ini hanya dijadikan sebagai penguat rasa masakan tertentu. Siala jelly juga memiliki potensi yang besar untuk dikembangkan di kota Padangsidimpuan.

Kegiatan sosialisasi tidak hanya memperkenalkan dan menjelaskan prosedur pembuatan siala jelly tapi juga diberikan sampel produk agar peserta sosialisasi dapat mengetahui bagaimana bentuk dan rasa siala jelly tersebut.

Tabel 2. Respon KWT Al-ikhsan Desa Simatohir terhadap Siala Jelly

\begin{tabular}{|c|c|c|c|c|}
\hline \multirow{2}{*}{ No } & \multirow{2}{*}{ Nama } & \multirow{2}{*}{ Umur (Tahun) } & \multicolumn{2}{|c|}{ Suka/tidak suka } \\
\hline & & & suka & tidak suka \\
\hline 1 & Sri Indah Komala & 19 & $\checkmark$ & \\
\hline 2 & Rosliana & 40 & $\checkmark$ & \\
\hline 3 & Dasni Sartika & 29 & $\checkmark$ & \\
\hline 4 & Puspa Herawati & 52 & $\checkmark$ & \\
\hline 5 & Meliani & 35 & $\checkmark$ & \\
\hline 6 & Samsidar & 38 & $\checkmark$ & \\
\hline 7 & Jubaidah Sitanggang & 46 & $\checkmark$ & \\
\hline 8 & Gongsani & 44 & $\checkmark$ & \\
\hline 9 & Rosmina & 42 & $\checkmark$ & \\
\hline 10 & Rahmadani Harahap & 26 & $\checkmark$ & \\
\hline 11 & Irna Dahlina Siregar & 22 & $\checkmark$ & \\
\hline 12 & Hotma Riani & 34 & $\checkmark$ & \\
\hline 13 & Nur Saulan & 33 & $\checkmark$ & \\
\hline 14 & Derliana & 29 & $\checkmark$ & \\
\hline 15 & Rika Rahayu & 24 & $\checkmark$ & \\
\hline
\end{tabular}




\begin{tabular}{lll}
16 & Rosmawati & 36 \\
17 & Zubaidah & 44 \\
18 & Maya & 19 \\
19 & Indah & 21 \\
20 & Irma & 31 \\
\hline
\end{tabular}

Pada Tabel 1 dapat dilihat bahwa terdapat 20 koresponden dari berbagai tingkat usia. Koresponden bertujuan untuk menentukan bagaimana respon masyarakat desa Simatohir terhadap rasa siala jelly. Dari 20 koresponden diketahui semua peserta sosialisasi menyukai rasa siala jelly (Tabel 1). Hasil sosialisasi siala jelly pada masyarakat menunjukkan respon yang baik. Respon masyarakat tersebut dapat dijadikan sebagai dasar bahwa siala jelly berpotensi besar untuk dikembangkan di kota Padangsidimpuan.

\section{KESIMPULAN}

Kegiatan sosialisasi pembuatan siala jelly kepada masyarakat desa Simatohir berjalan dengan lancar dilihat dari antusias peserta dalam menyimak materi dan mengajukan beberapa pertanyaan. Hasil kuisoner yang diberikan kepada peserta menunjukkan

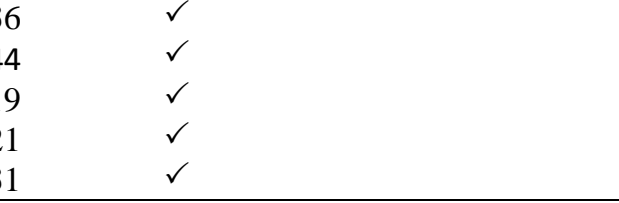

bahwa semua peserta menyukai rasa siala jelly. Masyarakat setempat mengharapkan kegiatan ini bisa menjadi salah satu bentuk usaha kreatif yang mampu meningkatkan kesejahteraan mereka.

\section{DAFTAR PUSTAKA}

Hudaya, A, 2010. Uji Antioksidan dan Antibakteri Ekstrak Air Bunga Kecombrang (Etlingera Elatior) sebagai Pangan Fungsional terhadap Staphylococcus aureus dan Escherichia coli. [Skripsi]. Jakarta. Universitas Islam Negeri Syarif Hidayatullah.

Naufalin, R. 2005. Kajian Sifat Antimikroba Bunga Kecombrang terhadap Berbagai Mikroba Patogen dan Perusak Pangan. [Disertasi]. Bogor. Program Pasca Sarjana, Institut Pertanian Bogor. 